\title{
An Investigation on the Properties of Palm-Based Polyurethane Solid Polymer Electrolyte
}

\author{
Farah Nadia Daud, ${ }^{1}$ Azizan Ahmad, ${ }^{1,2}$ and Khairiah Haji Badri ${ }^{1,2}$ \\ ${ }^{1}$ School of Chemical Sciences and Food Technology, Faculty of Science and Technology, Universiti Kebangsaan Malaysia, \\ 43600 Bangi, Selangor Darul Ehsan, Malaysia \\ ${ }^{2}$ Polymer Research Center, Faculty of Science and Technology, Universiti Kebangsaan Malaysia, 43600 Bangi, \\ Selangor Darul Ehsan, Malaysia
}

Correspondence should be addressed to Azizan Ahmad; azizan@ukm.my

Received 30 May 2013; Revised 9 February 2014; Accepted 20 February 2014; Published 30 March 2014

Academic Editor: Marek Cypryk

Copyright (C) 2014 Farah Nadia Daud et al. This is an open access article distributed under the Creative Commons Attribution License, which permits unrestricted use, distribution, and reproduction in any medium, provided the original work is properly cited.

\begin{abstract}
Palm-based polyurethane electrolyte was prepared via prepolymerization method between palm kernel oil polyol (PKO-p) and $2,4^{\prime}$-diphenylmethane diisocyanate (MDI) in acetone at room temperature with the presence of lithium trifluoromethanesulfonate $\left(\mathrm{LiCF}_{3} \mathrm{SO}_{3}\right)$. The effect of varying the concentration of $\mathrm{LiCF}_{3} \mathrm{SO}_{3}$ salt on the ionic conductivity, chemical interaction, and structural and morphological properties of the polyurethane solid polymer electrolyte was investigated. The produced film was analyzed using electrochemical impedance spectroscopy (EIS), attenuated total reflection Fourier transform infrared (ATR-FTIR), X-ray diffraction (XRD), and scanning electron microscopy (SEM). The EIS result showed that the highest ionic conductivity was at 30 wt $\% \mathrm{LiCF}_{3} \mathrm{SO}_{3}$ with a value of $1.6 \times 10^{-5} \mathrm{~S} \cdot \mathrm{cm}^{-1}$. Infrared analysis showed the interaction between lithium ions and amine group $(-\mathrm{N}-\mathrm{H})$ at $\left(3600-3100 \mathrm{~cm}^{-1}\right)$, carbonyl group $(-\mathrm{C}=\mathrm{O})$ at $\left(1750-1650 \mathrm{~cm}^{-1}\right)$, and ether group $(-\mathrm{C}-\mathrm{O}-\mathrm{C}-)$ at $\left(1150-1000 \mathrm{~cm}^{-1}\right)$ of the polyurethane forming polymer-salt complexes. The XRD result proved that $\mathrm{LiCF}_{3} \mathrm{SO}_{3}$ salt completely dissociates within the polyurethane film as no crystalline peaks of $\mathrm{LiCF}_{3} \mathrm{SO}_{3}$ were observed. The morphological study revealed that the films prepared have a good homogeneity and compatibility as no phase separation occurred.
\end{abstract}

\section{Introduction}

Since the discovery of ionic conductivity phenomenon in solid state by Faraday in the 1800 s, numerous studies have been conducted on polymer electrolytes pioneered by Peter Wright and Michel Armand who had introduced the first new class of solid ionic conductors in the 1970s [1]. Studies showed that liquid electrolyte has higher ionic conductivity compared to other electrolyte systems. However, it has several disadvantages, namely, leakage, gas formation during operation, and difficulty in handling for portable applications, which has resulted in increasing studies conducted on solid polymer electrolyte given its potential for applications in solid batteries, electrochromic windows, sensors, fuel cell, and others [2].

However, most of the current researches focus on the production of petrochemical based polymers such as polyethylene oxide (PEO) compared to polymers based on natural resources. Awareness of the importance of safe and environmental friendly sources of polymer has resulted in the studies replacing the dependence on petrochemical based polymers conductors. Moreover, with the current price hike of petroleum, the use of raw materials based on natural resources for industrial purposes also has increased. Palm oil-based products have become one of the alternatives for the production of polyols for polyurethane products [3].

Polyurethane is a copolymer that consists of urethane linkages $(-\mathrm{NHCOO})$ in its molecular structure. It is typically made by the reaction of a polyester or polyether polyol with diisocyanate. As a block copolymer, it has a unique multiphase structure consisting of soft segments and hard segments that are suitable as matrix materials in polymer electrolyte. Studies carried out by Badri et al. [4] described the 
method of producing monoester polyol (PKO-p) from palm kernel oil (PKO).

One of the approaches to produce polyurethanes is through prepolymerization technique in the presence of a solvent. This gives the advantage of lower isocyanate vapor levels and heat reduction of the final reaction compared to a single step polymerization. A single step polymerization of polyurethane gives off heat during formation of the urethane bonds and might cause shrinkage problem. Meanwhile, prepolymerization allows for partial heat dissipation prior to the formation of polyurethane as discussed elsewhere [5-7].

In this research, polyurethane was produced via prepolymerization method between PKO-p and 2, 4' -diphenylmethane diisocyanate (MDI) in acetone at room temperature. The effect of different concentrations of $\mathrm{LiCF}_{3} \mathrm{SO}_{3}$ salt on the ionic conductivity, chemical interaction, and structural and morphological properties of the polyurethane solid polymer electrolyte was investigated using electrochemical impedance spectroscopy (EIS), attenuated total reflection Fourier transform infrared (ATR-FTIR), X-ray diffraction (XRD), and scanning electron microscopy (SEM).

\section{Experimental}

2.1. Materials. Palm kernel oil-based polyol (PKO-p) was prepared as described by Badri et al. [4]. 2,4'-diphenylmethane diisocyanate (MDI) was purchased from Cosmopolyurethane (M) Sdn. Bhd, Port Klang, Malaysia. Acetone was supplied by Systerm Sdn. Bhd., Shah Alam, Malaysia. Polyethylene glycol (PEG) and lithium trifluoromethanesulfonate $\left(\mathrm{LiCF}_{3} \mathrm{SO}_{3}\right)$ were purchased from SigmaAldrich Sdn. Bhd., Kuala Lumpur, Malaysia. All materials were used without further purification.

2.2. Preparation of Prepolymerized Polyurethane (PU). The method used by Wong and Badri [5] was followed. PKO$\mathrm{p}$ and MDI were separately dissolved in acetone at room temperature to form urethane prepolymer. The amount of $\mathrm{LiCF}_{3} \mathrm{SO}_{3}$ salt was varied at 5 to $30 \mathrm{wt} \%$. The $\mathrm{LiCF}_{3} \mathrm{SO}_{3}$ salt was dissolved in the $\mathrm{PKO}-\mathrm{p}$ and stirred via magnetic bar for $30 \mathrm{~min}$. The MDI was then added into the PKO-p drop-wise and the mixture was stirred for another $5 \mathrm{~min}$ and casted into a Teflon plate. The solvent was allowed to slowly evaporate in a fume hood at room temperature for $24 \mathrm{~h}$. The films were yellow in color, translucent, and free standing.

2.3. Measurements. The ionic conductivity measurements were carried out by EIS using a high frequency resonance analyzer (HFRA; Solartron 1260, Schlumberger) with applied frequency ranging from 0.1 to $10^{6} \mathrm{~Hz}$ at a perturbation voltage of $1000 \mathrm{mV}$. The disc-shaped sample of $16 \mathrm{~mm}$ diameter was sandwiched between two stainless steel blocking electrodes. The ATR-IR spectrum was recorded by Perkin Elmer Spectrum 2000 in the range of 4,000 to $650 \mathrm{~cm}^{-1}$ with a scanning resolution of $4 \mathrm{~cm}^{-1}$. The analysis was conducted to study the interaction between $\mathrm{LiCF}_{3} \mathrm{SO}_{3}$ salt and the functional groups presence in polyurethane polymeric chain. XRD model D5000 Siemen was used to determine presence of crystalline
TABLE 1: The effect of $\mathrm{LiCF}_{3} \mathrm{SO}_{3}$ salt on the ionic conductivity of the polymer electrolyte.

\begin{tabular}{lc}
\hline $\mathrm{LiCF}_{3} \mathrm{SO}_{3},(\mathrm{wt} \%)$ & Ionic conductivity $(\sigma),\left(\mathrm{S} \cdot \mathrm{cm}^{-1}\right)$ \\
\hline 0 & $\sim 10^{-12}$ \\
5 & $1.8 \times 10^{-8}$ \\
10 & $1.3 \times 10^{-7}$ \\
15 & $6.6 \times 10^{-7}$ \\
20 & $4.0 \times 10^{-6}$ \\
25 & $4.5 \times 10^{-6}$ \\
30 & $1.6 \times 10^{-5}$ \\
\hline
\end{tabular}

or amorphous phase as a function of salt concentration. The data was collected at diffraction angle $2 \theta$ of $5^{\circ}$ to $60^{\circ}$ at the rate of $0.04^{\circ} \cdot \mathrm{s}^{-1}$. The morphologies of the cross-sectioned polymer electrolytes were analyzed using SEM Philip model XL30 at 1000x magnifications with $17 \mathrm{kV}$ electron beam. The thickness of the film obtained ranged from 0.11 to $0.17 \mathrm{~mm}$. The whole analysis was conducted at room temperature.

\section{Results and Discussion}

3.1. Ionic Conductivity. In the complex impedance plot, the real quantity $Z^{\prime}$ ( $x$-axis) was plotted against $Z^{\prime \prime}$ ( $y$-axis) which displayed the polymer electrolytes characteristics as an arc followed by linear spike that was a straight line inclined to the real axis. The bulk resistance $\left(R_{b}\right)$ of the electrolyte system was determined from an impedance plot where the ionic conductivity $(\sigma)$ was calculated from $R_{b}$ that was obtained from the intercept on the real axis $\left(Z^{\prime}\right)$, the film thickness $(l)$, and the contact area of the thin film $(A=$ $\left.\pi r^{2}=\pi(0.80 \mathrm{~cm})^{2}=2.01 \mathrm{~cm}^{2}\right)$ according to the equation $\sigma=\left[l /\left(A R_{b}\right)\right][8,9]$. Table 1 shows the conductivity of PU$\mathrm{LiCF}_{3} \mathrm{SO}_{3}$ electrolyte at varying concentration of $\mathrm{LiCF}_{3} \mathrm{SO}_{3}$ salt conducted at room temperature. The ionic conductivity increased with increasing concentration of $\mathrm{LiCF}_{3} \mathrm{SO}_{3}$ salt. The ionic conductivity increased three magnitudes compared to pristine $\mathrm{PU}$, with the addition of only $5 \mathrm{wt} \% \mathrm{LiCF}_{3} \mathrm{SO}_{3}$ $\left(1.8 \times 10^{-8} \mathrm{~S} \cdot \mathrm{cm}^{-1}\right)$. The highest conductivity was recorded at $30 \mathrm{wt} \% \mathrm{LiCF}_{3} \mathrm{SO}_{3}$ with conductivity of $1.6 \times 10^{-5} \mathrm{~S} \cdot \mathrm{cm}^{-1}$. This increment was contributed by the number of conducting species in the electrolyte caused by ion dissociation of $\mathrm{LiCF}_{3} \mathrm{SO}_{3}$. This occurred due to the presence of coordinating atoms in the polymer host $[10,11]$. The conducting species or free mobile ions present in the polymer may increase the amorphous structure of the polymer host through favorable free volume; thus, it eases the ion migration $[12,13]$. The ion transport phenomenon was further discussed in the IR spectroscopy analysis.

3.2. IR Spectroscopy Analysis. Previous studies [14-17] have reported the presence of strong hydrogen-bonding interaction in poly(ether-urethane) that leads to changes in PU microstructure consisting of soft and hard segments. The nature of the interaction and coordination of $\mathrm{Li}^{+}$and $\mathrm{CF}_{3} \mathrm{SO}_{3}{ }^{-}$ions transport within the PU chains was analyzed by mean of the IR spectrum [18]. In the hard segment, 


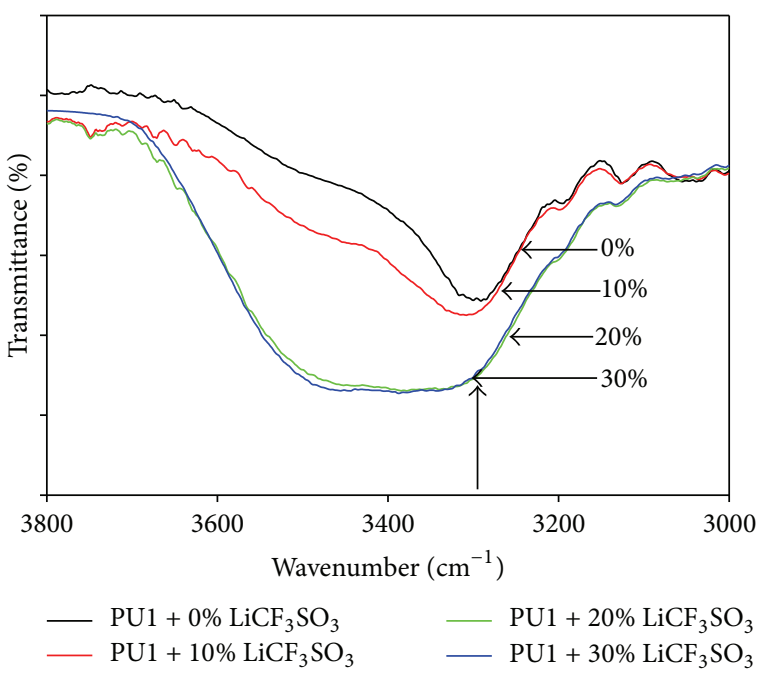

Figure 1: The N-H peak of PU at $3290 \mathrm{~cm}^{-1}$ shifted to the right as the concentration of the lithium salt increased.

the urethane groups have electrostatic charges at hydrogen, oxygen, and nitrogen atoms forming dipoles which attract another atom of opposite charge. The main functional groups in the regions such as $3600-3100 \mathrm{~cm}^{-1}$ (the hydrogen bonded $\mathrm{N}-\mathrm{H}$ stretching mode and the free $\mathrm{N}-\mathrm{H}$ stretch), 1750$1650 \mathrm{~cm}^{-1}$ (the carbonyl symmetric stretching vibration or amide band) $\left(-\mathrm{C}=\mathrm{O}\right.$ ), and $1150-1000 \mathrm{~cm}^{-1}$ (the $-\mathrm{C}-\mathrm{O}-\mathrm{C}-$ stretch) were identified to discern the effect of $\mathrm{LiCF}_{3} \mathrm{SO}_{3}$ on the chemical interaction of the PU electrolyte. Figure 1 exhibited that the N-H peak of PU at $3290 \mathrm{~cm}^{-1}$ shifted to a higher wave number as the concentration of the lithium salt increased, indicating that free $\mathrm{N}-\mathrm{H}$ was generated and there was less hard-hard segment hydrogen bonds left $[19,20]$.

Peak of ether group (-C-O-C-) at $1017-1029 \mathrm{~cm}^{-1}$ (Figure 2) became intense while peak at $1105 \mathrm{~cm}^{-1}$ became almost a plateau due to overlapping peaks contributed by the $\mathrm{Li}^{+}$bonded ether group, free bonded ether, and hydrogen ether.

However, Figure 3 indicated a reduction in intensity of the hydrogen bonded carbonyl group at $1707 \mathrm{~cm}^{-1}$ as the concentration of salt increased. Meanwhile, peak of the nonhydrogen bonded carbonyl urethane group at $1720 \mathrm{~cm}^{-1}$ shifted to a lower frequency due to the interaction with lithium ions. From the observation conducted on the ATR-IR spectroscopy analysis, it can be deduced that lithium salts had interacted with both the hard segments which were the $\mathrm{N}-\mathrm{H}$ and $\mathrm{C}=\mathrm{O}$ and also the soft segment which was $-\mathrm{C}-\mathrm{O}-\mathrm{C}-$ of polyurethane and affected the crystallinity of polyurethane as observed in the XRD analysis [19].

3.3. X-Ray Diffraction Analysis (XRD). The X-ray diffraction analysis is used to determine the structure, complexation, and crystallization of the polymer matrix. The effect of complexation of $\mathrm{PU}-\mathrm{LiCF}_{3} \mathrm{SO}_{3}$ system was investigated by performing XRD analysis where the appearance of the amorphous region or the reduction of the crystalline region would

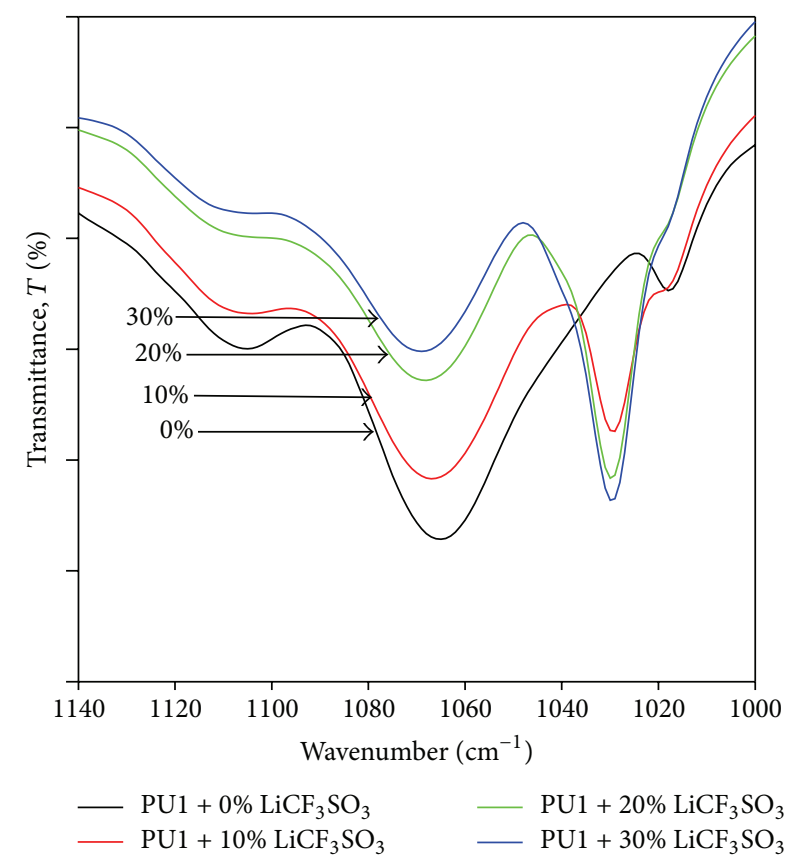

Figure 2: Peak of ether group (-C-O-C-) at $1017-1029 \mathrm{~cm}^{-1}$ and $1105 \mathrm{~cm}^{-1}$ for the free bonded ether and hydrogen ether.

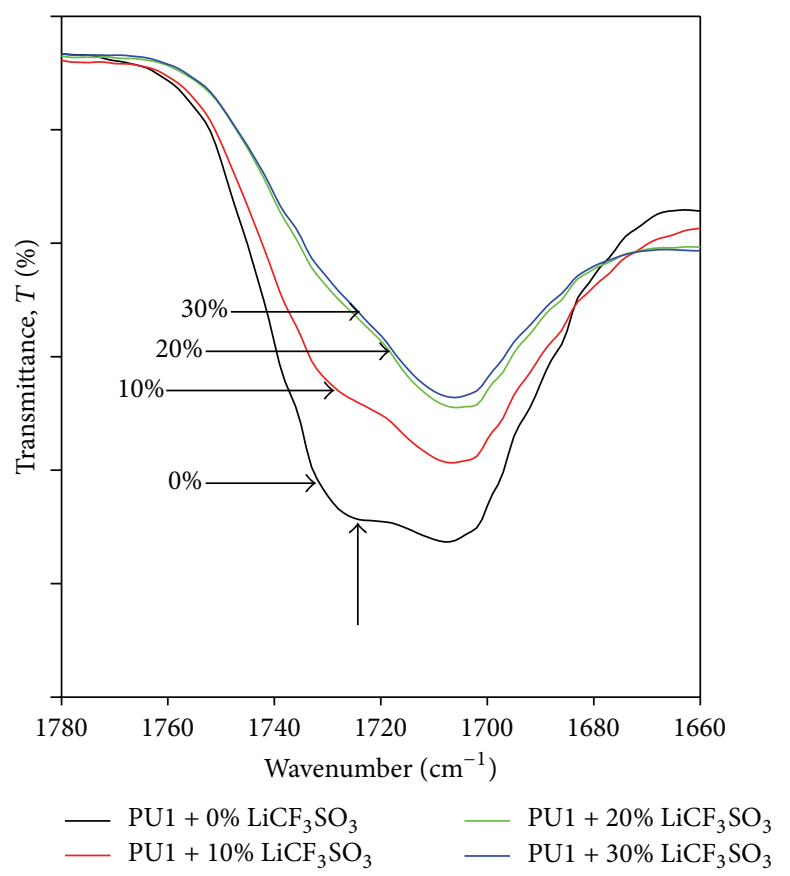

FIGURE 3: The hydrogen-bonded carbonyl group at $1707 \mathrm{~cm}^{-1}$ and the nonhydrogen bonded carbonyl urethane group at $1720 \mathrm{~cm}^{-1}$.

result in high ionic conductivity compared to the crystalline and semicrystalline region as reported by Su'ait et al. [21]. The measurement was conducted in the range of $5^{\circ}-60^{\circ}$ at diffraction angle of $2 \theta$. Figure 4 shows the XRD pattern of pristine $\mathrm{PU}$ and the $\mathrm{PU}-\mathrm{LiCF}_{3} \mathrm{SO}_{3}$ to study the change of crystalline structure upon addition of different weight 


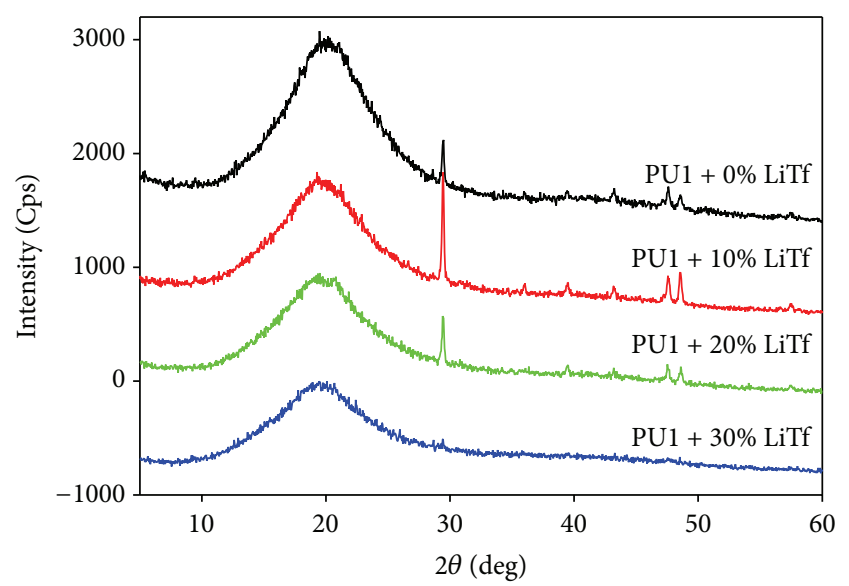

FIGURE 4: XRD patterns of PU1 with varying amount of $\mathrm{LiCF}_{3} \mathrm{SO}_{3}$.

percentages $(10 \%, 20 \%$, and $30 \%)$ of $\mathrm{LiCF}_{3} \mathrm{SO}_{3}$. From the diffractogram, we can observe that the pristine PU film was a semicrystalline polymer with a broad hump at $20^{\circ}$ and crystalline peaks at $31^{\circ}, 52^{\circ}$, and $53^{\circ}$. As the salt addition increased, the crystalline peaks decreased and disappeared as $30 \mathrm{wt} \%$ of $\mathrm{LiCF}_{3} \mathrm{SO}_{3}$ was added into PU. The hump becomes broader and flatter proving that the PU became more amorphous upon the salt addition [22]. In amorphous state, greater ionic diffusivity can occur as ions can move in the amorphous phase freely because of low energy barrier. Besides, the amorphous polymer exhibits more flexible backbone which can increase local chain mobility. Hence, the segmental motions of the polymer will also increase. This will then improve the transportation property of the electrolyte system [9].

3.4. Scanning Electron Microscopy (SEM). Figure 5 shows the SEM micrograph of the pristine PU film. It exhibited a clear and smooth surface. However, the presence of $\mathrm{LiCF}_{3} \mathrm{SO}_{3}$ in the PU film was obviously shown upon drying of the sample. Higher loading of the $\mathrm{LiCF}_{3} \mathrm{SO}_{3}$ gave more distribution of the $\mathrm{LiCF}_{3} \mathrm{SO}_{3}$ salt on the PU film. This was strongly supported by the XRD analysis where there was a reduction in the crystallinity of the sample. Thus, higher conductivity was observed. The micrographs of the PU electrolytes at 10, 20 , and $30 \mathrm{wt} \%$ showed the uniformly distributed spherical grains in the electrolyte system (Figures 6, 7, and 8). The more the appearance of the $\mathrm{LiCF}_{3} \mathrm{SO}_{3}$ salt on the PU film, the higher the conductivity increase.

\section{Conclusion}

In this study, palm-based polyurethane solid polymer electrolyte was successfully prepared via prepolymerization method. The highest conductivity obtained was 1.6 $\times 10^{-5} \mathrm{~S} \cdot \mathrm{cm}^{-1}$ at $30 \mathrm{wt} \%$ of $\mathrm{LiCF}_{3} \mathrm{SO}_{3}$. FTIR spectroscopy analysis confirmed that there was possible interaction that occurred between PU and lithium ions in the amine, ether, and carbonyl group. The structural analysis recorded by XRD

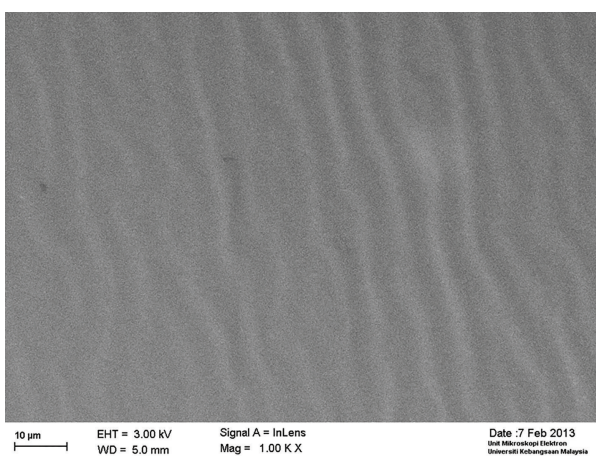

FIGURE 5: SEM micrograph of pristine polyurethane.

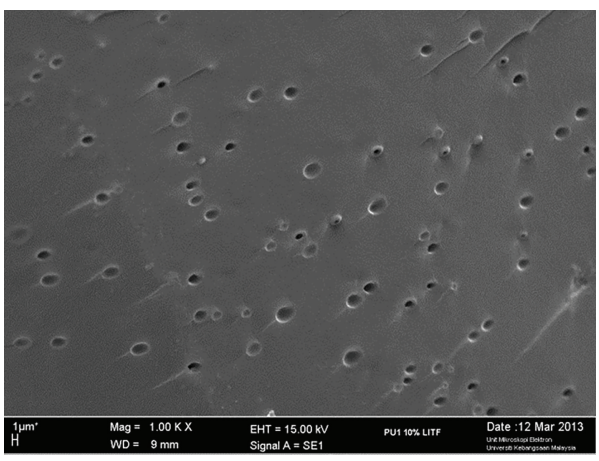

FIGURE 6: SEM micrograph of the PU film containing $10 \mathrm{wt} \%$ $\mathrm{LiCF}_{3} \mathrm{SO}_{3}$.

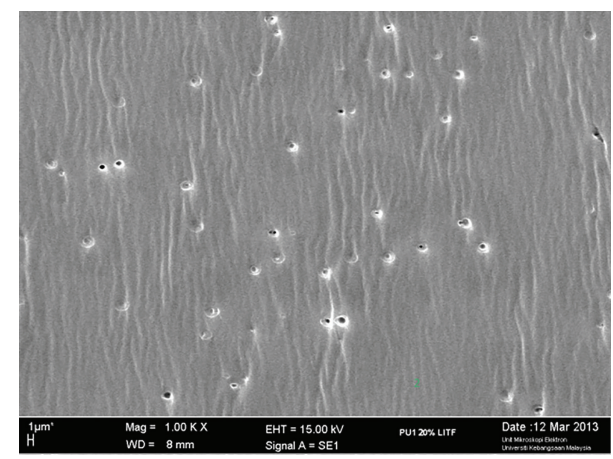

FIGURE 7: SEM micrograph of the PU film containing $20 \mathrm{wt} \%$ $\mathrm{LiCF}_{3} \mathrm{SO}_{3}$.

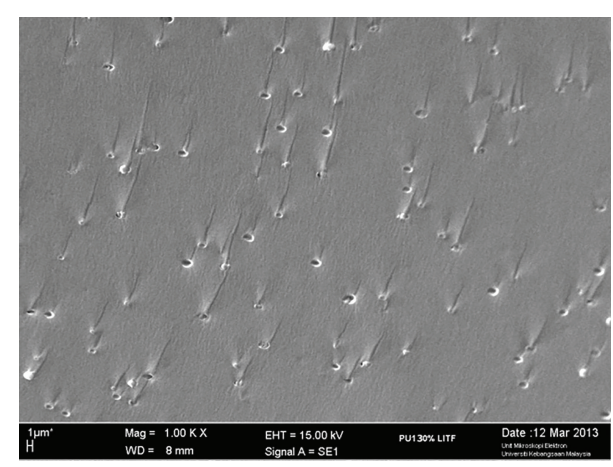

FIGURE 8: SEM micrograph of the PU film containing $30 \mathrm{wt} \%$ $\mathrm{LiCF}_{3} \mathrm{SO}_{3}$. 
showed the reduction of the PU crystalline phase at the highest conductivity.

\section{Conflict of Interests}

The authors declare that there is no conflict of interests regarding the publication of this paper.

\section{Acknowledgments}

This work was supported by School of Chemical Sciences and Food Technology as well as Polymer Research Center, Faculty of Science and Technology, and Universiti Kebangsaan Malaysia. It has been financially supported by Malaysia Ministry of Higher Education by research Grant no. FRGS/1/2011/TK/UKM/02/39 and Ministry of Science, Technology and Innovation by project no. 03-01-02-SF0949.

\section{References}

[1] M. B. Armand, P. G. Bruce, M. Forsyth, B. Scrosati, and W. Wieczorek, Polymer Electrolytes: Energy Materials, John Wiley and Sons, 2011.

[2] S. Rajendran, M. Sivakumar, and R. Subadevi, "Li-ion conduction of plasticized PVA solid polymer electrolytes complexed with various lithium salts," Solid State Ionics, vol. 167, no. 3-4, pp. 335-339, 2004.

[3] T. L. Ooi, A. Salmiah, A. H. Hazimah, and Y. J. Chong, "An Overview of R and D in Palm Oil-Based Polyols and Polyurethane in MPOB," A Bulletin of Palm Oil Developments, 2006.

[4] K. H. Badri, S. H. Ahmad, and S. Zakaria, "Production of a high-functionality RBD palm kernel oil-based polyester polyol," Journal of Applied Polymer Science, vol. 81, no. 2, pp. 384-389, 2001.

[5] C. S. Wong and K. H. Badri, "Chemical analyses of palm kernel oil-based polyurethane prepolymer," Material Sciences and Application, vol. 3, pp. 78-86, 2012.

[6] T. S. Velayutham, W. H. A. Majid, A. B. Ahmad, G. Y. Kang, and S. N. Gan, "Synthesis and characterization of polyurethane coatings derived from polyols synthesized with glycerol, phthalic anhydride and oleic acid," Progress in Organic Coatings, vol. 66, no. 4, pp. 367-371, 2009.

[7] S. Li, R. Vatanparast, and H. Lemmetyinen, "Cross-linking kinetics and swelling behaviour of aliphatic polyurethane," Polymer, vol. 41, no. 15, pp. 5571-5576, 2000.

[8] "Scanning electron microscope," in Surface Analysis Studies on Polymer Electrolyte Membranes Using Scanning Electron Microscope and Atomic Force Microscope, U. Ulaganathan, R. Nithya, S. Rajendran, and V. Kazmiruk, Eds., chapter 33, 2012.

[9] M. Y. A. Rahman, A. Ahmad, T. K. Lee, Y. Farina, and H. M. Dahlan, " $\mathrm{LiClO}_{4}$ salt concentration effect on the properties of PVC-modified low molecular weight LENR50-based solid polymer electrolyte," Journal of Applied Polymer Science, vol. 124, no. 3, pp. 2227-2233, 2012.

[10] A. Ahmad, M. Y. A. Rahman, S. P. Low, and H. Hamzah, "Effect of $\mathrm{LiBF}_{4}$ salt concentration on the properties of plasticized MG49-TiO 2 based nanocomposite polymer electrolyte," ISRN Materials Science, vol. 2011, Article ID 401280, 7 pages, 2011.
[11] M. S. Su'ait, A. Ahmad, H. Hamzah, and M. Y. A. Rahman, "Preparation and characterization of PMMA-MG49--LiClO solid polymeric electrolyte," Journal of Physics D: Applied Physics, vol. 42, Article ID 055410, 2009.

[12] S. Ramesh and G. P. Ang, "Impedance and FTIR studies on plasticized PMMA-LiN $\left(\mathrm{CF}_{3} \mathrm{SO}_{2}\right)_{2}$ nanocomposite polymer electrolytes," Ionics, vol. 16, no. 5, pp. 465-473, 2010.

[13] A. Ahmad, M. Y. A. Rahman, S. P. Low, and H. Hamzah, "Effect of $\mathrm{LiBF}_{4}$ salt concentration on the properties of plasticised MG49- $\mathrm{TiO}_{2}$ based nanocomposite polymer electrolyte," ISRN Materials Science, vol. 2011, Article ID 401280, 7 pages, 2011.

[14] W.-C. Chen, H.-H. Chen, T.-C. Wen, M. Digar, and A. Gopalan, "Morphology and ionic conductivity of thermoplastic polyurethane electrolytes," Journal of Applied Polymer Science, vol. 91, no. 2, pp. 1154-1167, 2004.

[15] T.-C. Wen, Y.-J. Wang, T.-T. Cheng, and C.-H. Yang, “The effect of DMPA units on ionic conductivity of PEG-DMPA-IPDI waterborne polyurethane as single-ion electrolytes," Polymer, vol. 40, no. 14, pp. 3979-3988, 1999.

[16] M. Digar, S. L. Hung, H. L. Wang, T. C. Wen, and A. Gopalan, "Study of ionic conductivity and microstructure of a crosslinked polyurethane acrylate electrolyte," Polymer, vol. 43, no. 3, pp. 681-691, 2001.

[17] S. C. Yoon and B. D. Ratner, "Surface and bulk structure of segmented poly(ether urethanes) with perfluoro chain extenders. 2. FTIR, DSC, and X-ray photoelectron spectroscopic studies," Macromolecules, vol. 21, no. 8, pp. 2392-2400, 1988.

[18] L. Verdolotti, S. Colini, G. Porta, and S. Iannace, "Effects of the addition of $\mathrm{LiCl}, \mathrm{LiClO}_{4}$, and $\mathrm{LiCF}_{3} \mathrm{SO}_{3}$ salts on the chemical structure, density, electrical, and mechanical properties of rigid polyurethane foam composite," Polymer Engineering and Science, vol. 51, no. 6, pp. 1137-1144, 2011.

[19] S. Wang, S. Jeung, and K. Min, "The effects of anion structure of lithium salts on the properties of in-situ polymerized thermoplastic polyurethane electrolytes," Polymer, vol. 51, no. 13, pp. 2864-2871, 2010.

[20] T.-C. Wen, Y.-L. Du, and M. Digar, "Compositional effect on the morphology and ionic conductivity of thermoplastic polyurethane based electrolytes," European Polymer Journal, vol. 38, no. 5, pp. 1039-1048, 2002.

[21] M. S. Su'ait, A. Ahmad, H. Hamzah, and M. Y. A. Rahman, "Effect of lithium salt concentrations on blended $49 \%$ poly(methyl methacrylate) grafted natural rubber and poly(methyl methacrylate) based solid polymer electrolyte," Electrochimica Acta, vol. 57, no. 1, pp. 123-131, 2011.

[22] S. Ramesh and A. K. Arof, "Structural, thermal and electrochemical cell characteristics of poly(vinyl chloride)-based polymer electrolytes," Journal of Power Sources, vol. 99, no. 1-2, pp. 41-47, 2001. 

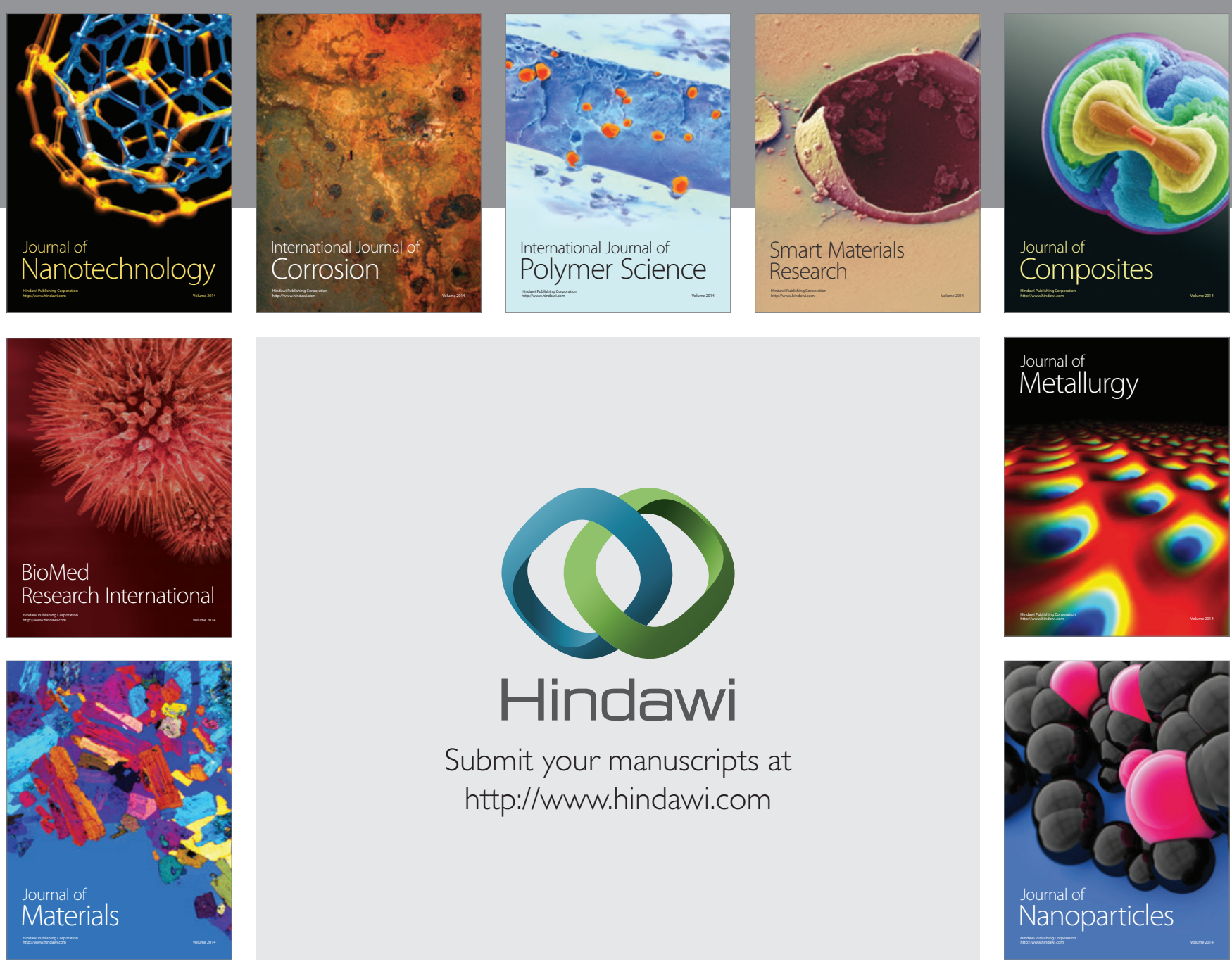

Submit your manuscripts at http://www.hindawi.com
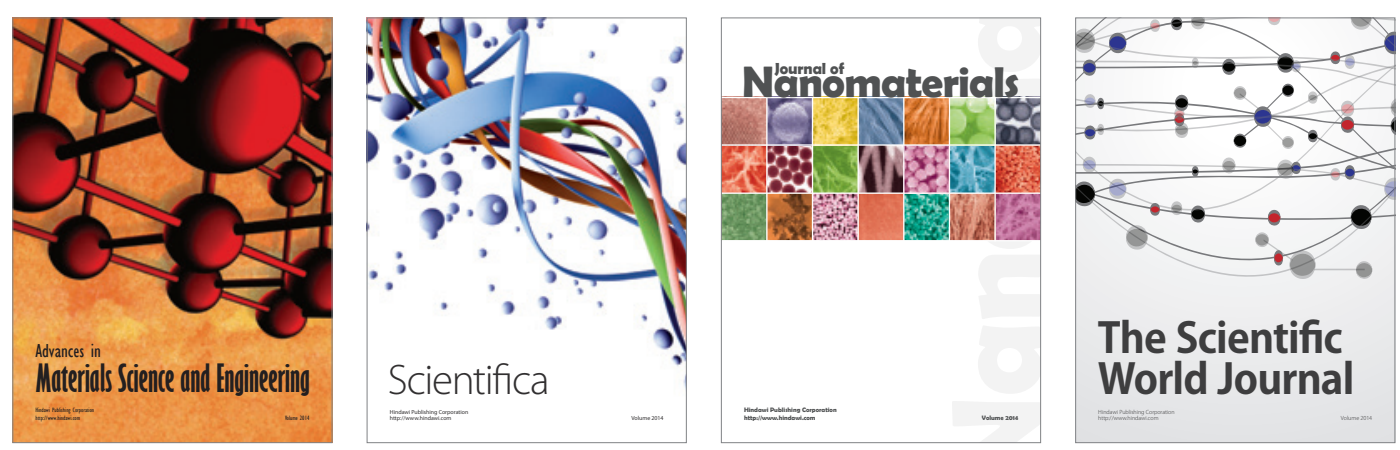

\section{The Scientific World Journal}
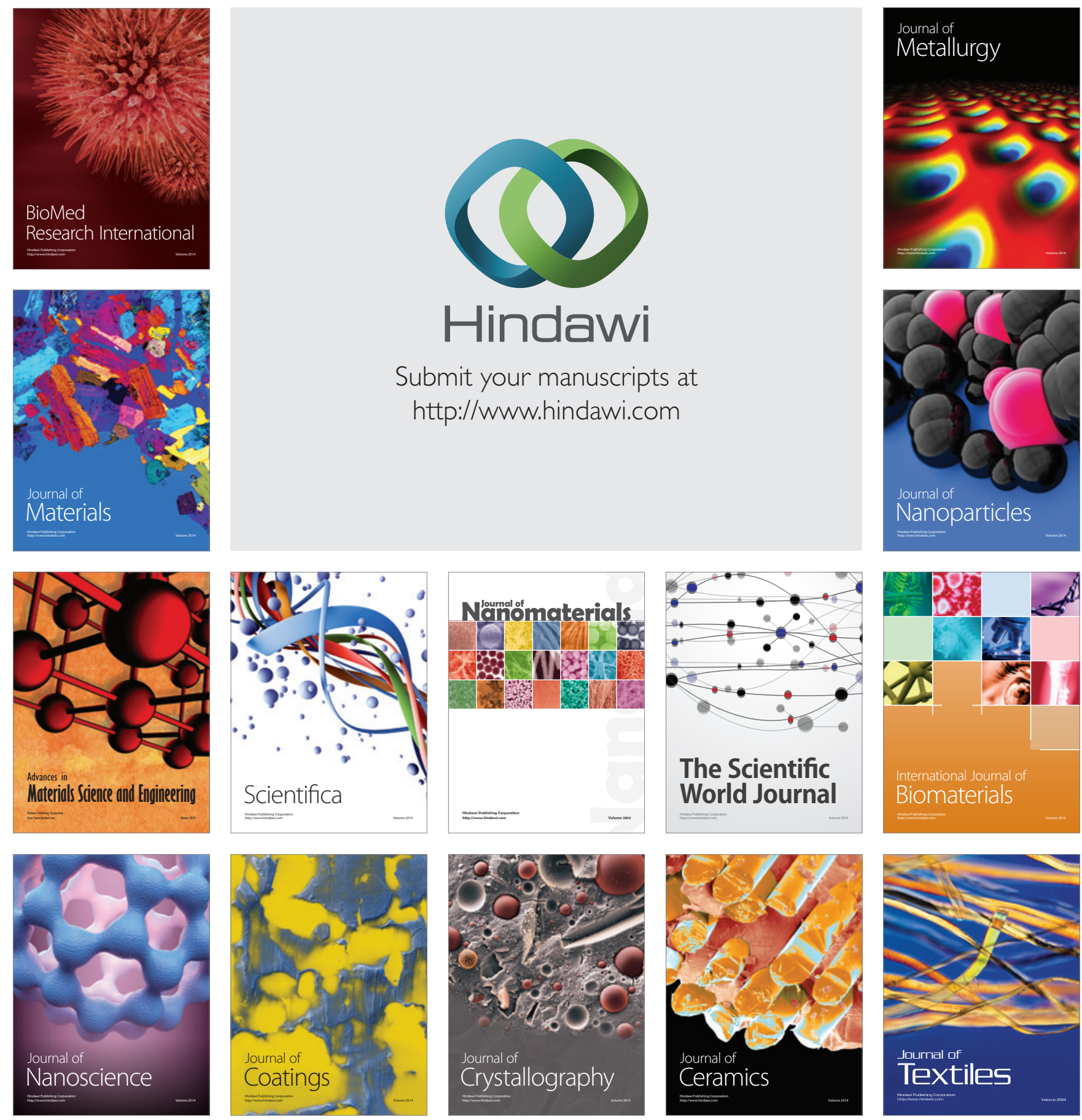